1. DCD (Paediatric Dentistry) Senior Registrar Department of Paediatric Dentistry, Rehman College of Dentistry, RMI, Peshawar.

2. M Clin Dent Paediatric Dentistry PG Dip Advanced Specialist Training in Paediatric Dentistry,

M Paed Dent,

Assistant Professor

Department of Paediatric Dentistry Rehman College of Dentistry, Peshawar.

3. DCD (Paediatric Dentistry) Assistant Professor Department of Paediatric Dentistry, KMU-Institute of Dental Sciences, Kohat.

4. M.Phil. Histopathology Assistant Professor Department of Oral Pathology KMU-Institute of Dental Sciences, Kohat.

5. BDS,

Demonstrato

Department of Paediatric Dentistry

Rehman College of Dentistry, Peshawar.

6. BDS

Demonstrator

Department of Paediatric Dentistry Rehman College of Dentistry, Peshawar.

Correspondence Address:

Dr. Madeeha Bangash

Department of Paediatric Dentistry,

Rehman College of Dentistry, RMI

Peshawar.

madeeha.bangash@rmi.edu.pk

\section{ASSOCIATION OF WEIGHT, HEIGHT AND BODY MASS INDEX WITH EARLY CHILDHOOD CARIES AMONG PRIMARY SCHOOL CHILDREN OF PESHAWAR.}

\begin{abstract}
Madeeha Bangash ${ }^{1}$, Laila Mustafa ${ }^{2}$, Sana Idrees ${ }^{3}$, Syed Omar Farooq $^{4}$, Ammara Sami $^{5}$,
\end{abstract} Gulandama Alam Khan ${ }^{6}$

ABSTRACT... Background: Dental caries is the single most common disease in children that has no pharmacological treatment. Global population exhibit some evidence of tooth decay affecting both genders, all races, socioeconomic status and age groups. Good oral health of early childhood has a vital role in overall health of school children. Objectives: The aim of this study was to determine association of weight, height, and body mass index (BMI) with early childhood caries (ECC) among primary school children of Peshawar. Study Design: Cross sectional study. Setting: Different Schools of Hayatabad, Peshawar. Period: Four months (January-April 2019). Material and Methods: Total of 240 school children, having sound heath with no systemic disease were included in the study. Children's weight and height were recorded and body mass index (BMI) was converted to z-scores and percentiles. The association of ECC with BMI, height and weight was determined. Results: The mean age, weight, height, body mass index, dmfs and Z-score was $5.3 \pm 0.79$ years, $20.34 \pm 3.75 \mathrm{~kg}, 3.47 \pm 0.246$ feet, $18.06 \pm 4.08 \mathrm{~kg} / \mathrm{m} 2$, $14.84 \pm 15.73$, and $1.14 \pm 1.22$ respectively. The association of early childhood caries among primary school children was not significant with age $(P=0.424)$, height $(P=0.622)$ and gender $(P=0.061)$. The association was highly statistically significant with $B M I(P<0.001)$. Conclusion: Children with higher ECC scores were significantly associated with BMI.

Key words: $\quad$ BMI, Dental Caries, ECC, Height, Weight.

Article Citation: Bangash M, Mustafa L, Idrees S, Farooq SO, Sami A, Khan GA. Association of weight, height and body mass index with early childhood caries among primary school children of Peshawar. Professional Med J 2019; 26(9):1592-1596. DOI: 10.29309/TPMJ/2019.26.09.3863

Article received on:

29/06/2019

Accepted for publication:

25/08/2019

Received after proof reading:

28/08/2019

\section{INTRODUCTION}

Dental caries is one of the most prevalent oral disease in children which can result in significant discomfort, pain and affects them psychologically. ${ }^{1-4}$ Dental caries also places a financial burden on parents as well as health care system of a country. Sound oral health is mandatory for mastication, phonation and provides an acceptable appearance which aid in early social contacts and is the basis of sustained oral health all the way through infancy into adolescence and adulthood. ${ }^{5}$ Diet is one most important causative factors for dental caries. Besides being a cause of dental caries, refined and processed food is also associated with high body mass index (BMI) scores which is an indicator of obesity.

According to American Academy of Pediatric Dentistry(AAPD), Early Childhood Caries (ECC) is defined as 'presence of one or more decayed (cavitated or non-cavitated) missing (due to caries) or filled tooth surfaces in any primary tooth in a child 71 months of age or younger. Significant associations have been reported in literature between ECC and obesity, and have drawn the conclusions that there is a link between the two. ${ }^{6,7}$ On other hand some large sample population based investigations have not found any significant association between BMI and caries experience when the confounders factors were controlled. ${ }^{8,9}$ 
Dental caries is a topic of extensive research throughout the world, however few studies focus on the link between childhood obesity and ECC. In addition, previous studies on the link between $\mathrm{BMI}$ and dental caries have inconsistent results. Since Pakistan is a developing country, people are shifting towards more processed and refined dietary choices. Moreover, there is a lack of knowledge and awareness regarding the dental and general health effects of consuming refined and processed food.

We hypothesized that ECC has a positive association with height, weight and BMI of children under 6 years. Therefore the aim of this study was to determine the association of weight, height and body mass index with early childhood caries among primary school children of Hayatabad, Peshawar.

\section{METHODOLOGY}

A total of 240 under 6 year school children (120 males and 120 females) from 5 private and 5 government schools of Hayatabad, Peshawar were included by cluster probability consecutive sampling technique. The written informed consent was taken from principals of each school. Children having sound health with no systemic disease, Pakistani national and less than 6 year with no first permanent eruption were included. Mentally and physically handicapped children were excluded.

After obtaining detailed history, weight in kilograms, height in meter and age in years, caries using dmfs (decayed, missing, and filled tooth) scores of the children were recorded. Cleaning the teeth with cotton rolls was done when necessary. Dental caries examination was carried with help of blunt explorer and disposable mouth mirror to see an indirect lingual region of the dentition in natural light. ${ }^{10}$ Children were weighed to the nearest 0.1 kilogram using a standard beam balance scale. Children's height was recorded to the nearest one centimeter with no shoes, heels together and head just touch the scale.

Body mass index was converted to BMI z-scores and percentile data using an online calculator for the purpose of comparing subjects of various ages and genders. The classification of BMI percentiles were classified into one of four categories, as per the center of disease center:

- Under-weight less than $5^{\text {th }}$ percentile,

- Normal weight from $5^{\text {th }}$ toless than $85^{\text {th }}$ percentile,

- Overweight from $85^{\text {th }}$ toless than $95^{\text {th }}$ percentile,

- $\quad$ Obese $\geq 95^{\text {th }}$ percentile. ${ }^{12}$

All the data was analyzed in SPSS version 20.0. Descriptive statistics were computed for all variables. Continuous variables like age, height, weight, dmfs, Z-score and BMI were computed as a mean and standard deviation. Frequencies and percentages were calculated for qualitative variable like age groups, BMl classes, height classes, gender and caries classes. Chi-square test was run to know the association between of weight, height and body mass index with early childhood caries. P-value less than or equal to 0.05 were considered as statistically significant.

\section{RESULTS}

Of total sample the common age was 5.5 years $n=120(50 \%)$ followed by 5 years $n=5(74 \%)$. The least number of cases were in age 3 years $n=2(0.8 \%)$. The BMI classes on basis of percentile and Z-score showed that most common categories were normal weight $n=93(38.8 \%)$ followed by overweight $n=63(33.3 \%)$ and obese $n=63(26.3 \%)$. Least number of cases were in underweight group $n=4(1.7 \%)$. Most frequent height range was 3.4 to 3.6 feet $n=106(44.2 \%)$ followed by 3.0 to 3.3 feet $n=73(30.4 \%)$. The least number of children belonged to 3.7 to 3.9 feet $n=61(25.4 \%)$ group. Males and females were equal in number $n=120(50 \%)$. Of $n=240$, $n=112(46.7 \%)$ had no caries and $n=128(53.3 \%)$ had caries. The details are given in Table-l.

The mean age, weight, height, body mass index, dmfs and Z-score was $5.3 \pm 0.79$ years, $20.34 \pm 3.75 \mathrm{~kg}, 3.47 \pm 0.246$ feet, $18.06 \pm 4.08 \mathrm{~kg} /$ $\mathrm{m}^{2}, 14.84 \pm 15.73$, and $1.14 \pm 1.22$ respectively Table-II. 
The association of early childhood caries among primary school children was not significant with age $(P=0.424)$, height $(P=0.622)$ and gender $(P=0.061)$. The association was highly statistically significant with $\mathrm{BMI}(\mathrm{P}<0.001)$. The number of children with early childhood caries were more obese and overweight than non-carious children. The details are shown in Table-III.

\begin{tabular}{|c|c|c|c|}
\hline \multirow{6}{*}{ Age categories (years) } & & Frequency & Percent \\
\hline & 3 & 2 & 0.8 \\
\hline & 4 & 44 & 18.3 \\
\hline & 5 & 74 & 30.8 \\
\hline & 5.5 & 120 & 50 \\
\hline & Total & 240 & 100 \\
\hline \multirow{5}{*}{ BMI classes } & under weight & 4 & 1.7 \\
\hline & normal weight & 93 & 38.8 \\
\hline & Overweight & 80 & 33.3 \\
\hline & Obese & 63 & 26.3 \\
\hline & Total & 240 & 100 \\
\hline \multirow{4}{*}{ Height categories (feet) } & 3.0-3.3 & 73 & 30.4 \\
\hline & 3.4-3.6 & 106 & 44.2 \\
\hline & $3.7-3.9$ & 61 & 25.4 \\
\hline & Total & 240 & 100 \\
\hline \multirow{3}{*}{ Gender } & Male & 120 & 50.0 \\
\hline & Female & 120 & 50.0 \\
\hline & Total & 240 & 100 \\
\hline \multirow{3}{*}{ Caries classes } & caries free group & 112 & 46.7 \\
\hline & carious group & 128 & 53.3 \\
\hline & Total & 240 & 100 \\
\hline
\end{tabular}

Table-I. Descriptive statistics of the age, BMI, height, gender and caries classes

\begin{tabular}{|l|c|c|}
\hline Variable & Mean \pm SD & Range \\
\hline Age (years) & $5.3 \pm 0.79$ & $3-6$ \\
\hline weight $(\mathrm{kg})$ & $20.34 \pm 3.75$ & $14-29$ \\
\hline Height (feet) & $3.47 \pm 0.246$ & $3-3.9$ \\
\hline Body mass index $\left(\mathrm{kg} / \mathrm{m}^{2)}\right.$ & $18.06 \pm 4.08$ & $13-32$ \\
\hline Dmfs & $14.84 \pm 15.73$ & $2-60$ \\
\hline Z-score & $1.14 \pm 1.22$ & $-2-4$ \\
\hline
\end{tabular}

Table-II. Mean and standard deviation of Age, weight, Height, Body mass index, DMFS and Z-score

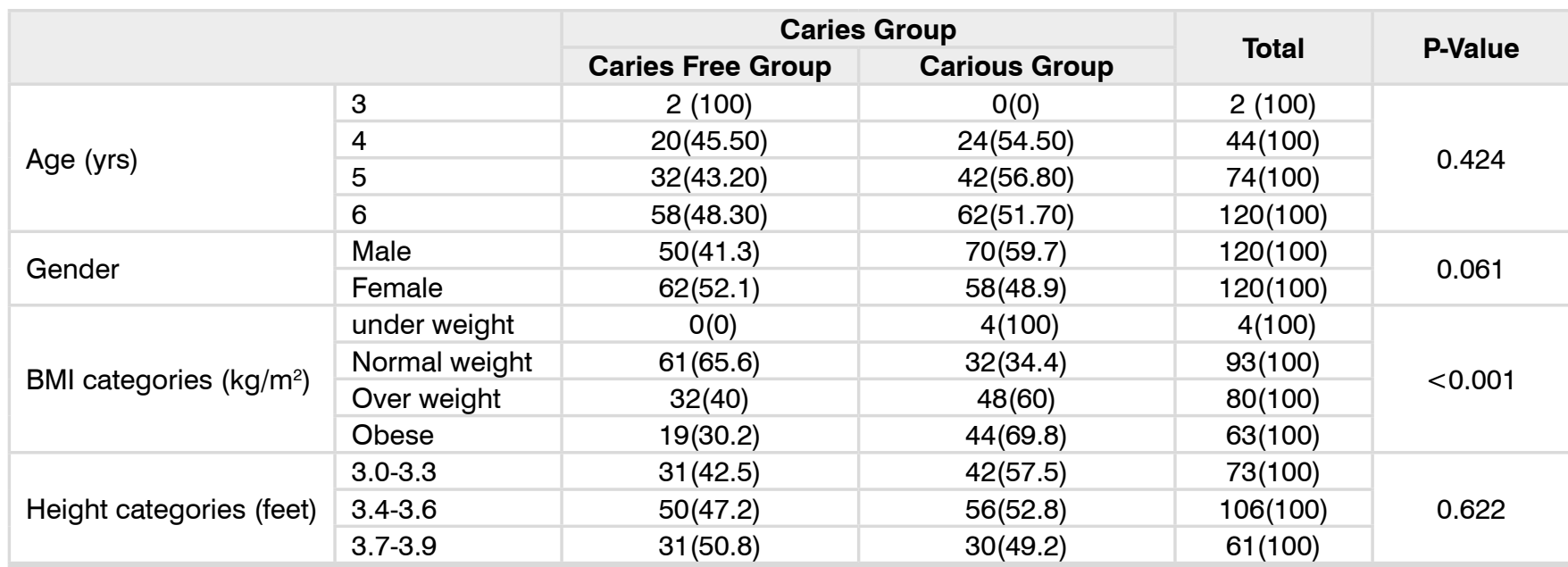

Table-III. Association of weight, height, body mass index and gender with early childhood caries among primary school children 


\section{DISCUSSION}

There are enormous changes in dietary habits during the past decades in developing countries causing high prevalence of dental caries. Poverty, unawareness and illness, together with insufficient food supplies, detrimental environments, social stress, and prejudice, still carries on as a network of interrelating factors which merge to create circumstances in which malnutrition flourishes. ${ }^{11}$

Results of this study show that early childhood caries among primary school children was not associated with age, height, weight and gender. The association of early childhood caries was significant with BMI. The number of children with early childhood caries were more obese and overweight than compared to children with low caries scores.

In this study we used the dmfs index to record the early childhood caries which is also used in previous studies. ${ }^{12,13} \mathrm{~A}$ study by Bagherian et al. ${ }^{12}$ on the association of dental caries and body mass index in preschool children reported that overweight children had higher dmfs score and children with more dental caries were prone to be overweight.

Willershausen et al. ${ }^{14}$ carried out a study on correlation of body mass index and early childhood caries. They reported a high correlation of childhood caries and obesity. In addition, gender was not significantly related to early childhood caries. Similarly Larsson et al. ${ }^{15}$ in their investigation showed that children with high values of dmft were more obese. These findings are in agreement with our study.

In contrast, association reported by Hong et al. ${ }^{16}$ showed no significant correlation between childhood obesity and caries in 2 to 6 years old children. The differences may be due to genetic, environmental and ethnic variations. Similarly there was no association for body mass index with age and dental caries in children reported in other studies. ${ }^{17,18}$

The oral health has a vital role in nutritional intake and general body health. Tooth loss as a result of dental caries has a detrimental effect on children's dietary habits. This is a common findings that elderly people with early tooth loss, show a deviation from preferred foods.

Inconsistent findings in previous research between body mass index and dental caries may account for a non-linear association. ${ }^{19}$ It is therefore recommended that future research should investigate the nature of the association between BMI and tooth decay in different populations, and determine how factors such as socioeconomic status affect the association between BMI and tooth decay.

\section{CONCLUSION}

Due to significant association of early childhood caries with obesity and overweight among school children it is suggested that dental professionals should counsel the population about weight, eating habits and food choices.

\section{Copyright $\subseteq 25$ Aug, 2019.}

\section{REFFERENCES}

1. Popoola B, Denloye O, Iyun O. Influence of parental socioeconomic status on caries prevalence among children seen at the University College Hospital, Ibadan. Ann Ib Postgrad Med 2013; 11(2):81-86.

2. Moses J, Rangeeth B, Gurunathan D. Prevalence of dental caries, socio-economic status and treatment needs among $\mathbf{5}$ to $\mathbf{1 5}$ year old school going children of Chidambaram. J Clin Diagn Res 2011; 5(1):146-51.

3. Davidson K, Schroth RJ, Levi JA, et al. Higher body mass index associated with severe early childhood caries. Biomed Cent Pediatr 2016; 16(1):137-43.

4. Faker K, Tostes MA, Paula VACd. Impact of untreated dental caries on oral health-related quality of life of children with special health care needs. Braz Oral Res 2018; 32(18):e117-e21.

5. Javed F, Feng C, Kopycka-Kedzierawski DT. Incidence of early childhood caries: A systematic review and meta $\square$ analysis. J Investigat Clin Dent 2017; 8(4):e12238-42.

6. Reifsnider E, Mobley C, Mendez DB. Childhood obesity and early childhood caries in a WIC population. $J$ Multicul Nurs Health 2004; 10(2):24-31. 
7. Vázquez-Nava F, Vázquez-Rodríguez EM, SaldívarGonzález $\mathrm{AH}$, et al. Association between obesity and dental caries in a group of preschool children in Mexico. J Public Health Dent 2010; 70(2):124-30.

8. Hong L, Ahmed A, McCunniff M, Overman P, Mathew M. Obesity and dental caries in children aged $2 \square 6$ years in the United States: National health and nutrition examination survey $1999 \square 2002$. J Public Health Dent 2008; 68(4):227-33.

9. Dye BA, Shenkin JD, Ogden CL, et al. The relationship between healthful eating practices and dental caries in children aged 2-5 years in the United States, 1988-1994. J Am Dent Assoc 2004; 135(1):55-66.

10. WHO. Oral health surveys, basic method. 4 th ed., Geneva: WHO. 1997.

11. Edalat A, Abbaszadeh $M$, Eesvandi $M$, Heidari $A$. The relationship of severe early childhood caries and body mass index in a group of 3-to 6-year-old children in Shiraz. J Dent 2014; 15(2):68-73.

12. Bagherian A, Sadeghi M. Association between dental caries and age-specific body mass index in preschool children of an Iranian population. Ind $\mathrm{J}$ Dent Res 2013; 24(1):66-70.

13. Al-Janabi WH. Association between dental caries and age specific body mass index in Hilla city, Babylon province, Iraq. J Int Dent Med Res 2019; 12(1):156-59.
14. Willershausen B, Moschos D, Azrak B, Blettner M. Correlation between oral health and body mass index (BMI) in 2071 primary school pupils. Eur J Dent 2007; 12(7):295-9.

15. Larsson B, Johansson I, Weinehall L, Hallmans G, Ericson T. Cardiovascular disease risk factors and dental caries in adolescents: effect of a preventive program in Northern Sweden. Acta paediatrica 1997; 86(1):63-71.

16. Hong L, Ahmed A, McCunniff M, Overman P, Mathew M. Obesity and dental caries in children aged $2 \square 6$ years in the United States: National health and nutrition examination survey 1999-2002. J Public Health Dent 2008; 68(4):227-33.

17. Macek MD, Mitola DJ. Exploring the association between overweight and dental caries among US children. Pediatr Dent 2006;28(4):375-80.

18. Sadeghi M, Alizadeh F. Association between dental caries and body mass index-for-age among 6-11-year-old children in Isfahan in 2007. J Dent Res Dent Clin Dental Pros 2007; 1(3):119-24.

19. Hooley M, Skouteris H, Boganin C, Satur J, Kilpatrick $\mathrm{N}$. Body mass index and dental caries in children and adolescents: A systematic review of literature published 2004 to 2011. System Rev 2012; 1(1):57-60.

\begin{tabular}{|c|c|c|c|}
\hline \multicolumn{4}{|c|}{ AUTHORSHIP AND CONTRIBUTION DECLARATION } \\
\hline Sr. \# & Author-s Full Name & Contribution to the paper & Author $=\mathbf{s}$ Signature \\
\hline 1 & Madeeha Bangash & Principal Author & 28 \\
\hline 2 & Laila Mustafa & Co-author & \\
\hline 3 & Sana Idrees & Co-author & \\
\hline 4 & Syed Omar Farooq & Statistical analysis & We \\
\hline 5 & Ammara Sami & Clinical Investigator & in \\
\hline 6 & Gulandama Alam Khan & Clinical Investigator & (1) \\
\hline
\end{tabular}

